\title{
Analgesic Effect of Pre-Incisional Peritonsillar Infiltration of Ketamine for Post-Tonsillectomy Pain in Children
}

\author{
Nabil A. Sarhan ${ }^{*}$, Mohammed A. Fatahalla1, Mostafa E. M. Ahmed ${ }^{2}$, Haitham A. M. Osman² \\ ${ }^{1}$ Otorhinolaryngology, Faculty of Medicine, Al-Azhar University, Damietta, Egypt \\ ${ }^{2}$ Anesthesia and Intensive Care, Faculty of Medicine, Al-Azhar University, Assiut, Egypt \\ Email: *nabelent@yahoo.com
}

How to cite this paper: Sarhan, N.A., Fatahalla, M.A., Ahmed, M.E.M. and Osman, H.A.M. (2018) Analgesic Effect of Pre-Incisional Peritonsillar Infiltration of Ketamine for Post-Tonsillectomy Pain in Children. International Journal of Otolaryngology and Head \& Neck Surgery, 7, 317-329.

https://doi.org/10.4236/ijohns.2018.76032

Received: September 17, 2018

Accepted: November 6, 2018

Published: November 9, 2018

Copyright $\odot 2018$ by authors and Scientific Research Publishing Inc. This work is licensed under the Creative Commons Attribution International License (CC BY 4.0).

http://creativecommons.org/licenses/by/4.0/

\begin{abstract}
Objective: Two different concentrations of ketamine $0.5 \mathrm{mg} / \mathrm{kg}, 0.25 \mathrm{mg} / \mathrm{kg}$ were applied to both tonsils perioperatively to check analgesic effect postoperatively in children. This study done at Department of anesthesia and otorhinolaryngology, faculty of medicine, Al-Azhar University hospitals, and the medical ethics committee. The study was conducted in the ENT operating theatre, Al-Azhar University Hospitals, from Jan. 2017 to June 2018. Methodology: We divided patients into 3 groups K1, K2 and S each group 25 patients, group $\mathrm{K} 1 \mathrm{had} 0.25 \mathrm{mg}$ ketamine, group $\mathrm{k} 2 \mathrm{had} 0.5 \mathrm{mg}$ ketamine and group $\mathrm{S}$ had normal saline as a control group. These groups assessed intraoperatively by Heart rate and main arterial pressure (MAP) were recorded at the intervals together with Ventilation parameters. Postoperative pain assessment by using Children's Hospital of Eastern Ontario Pain Scale (CHEOPS). The sedative condition was assessed with the Wilson sedation scale at 5, 15,30, and $60 \mathrm{~min}$ after entrance to the PACU. CHEOPES was recorded only when patient modified Wilson sedation score was one. Incidences of postoperative complications as: blood loss, dysphagia, nausea and vomiting were noted and demonstrated; hallucinations will be observed and recorded. Results: There were no significant differences among the groups regarding age, gender and weight. There were no significant differences among the groups with respect to the demographic data, duration of surgery or anesthesia, and intraoperative blood loss. As regarding hemodynamics, mean blood pressure was significantly lower in group (K1) than group $\mathrm{S}$ (control group) at 20 and 30 minutes after injection of ketamine and significantly lower in group (K2) than group S (control group) at 20 and 30 minutes after injection of ketamine with no difference between group (K1) and (K2). There was a significant statistical difference in analgesia duration per hours and frequency of analgesics used over 24 hours between three groups, the
\end{abstract}


duration was longer in group (K1) and (K2) and frequency of analgesics used over 24 hours ( $\mathrm{P}$ value $<0.05$ ). Regarding postoperative complications, there was no significant statistical differences as regard nausea and vomiting, but the percentage of dysphagia is significantly higher in group S (control group) than group (K1) and group (K2). Conclusions: In our study, we found that preincisional peritonsillar infiltration of $0.25 \mathrm{mg} / \mathrm{kg}$ or $0.5 \mathrm{mg} / \mathrm{kg}$ of ketamine given at approximately three minutes before surgery provides efficient pain relief during $24 \mathrm{~h}$ after surgery, decrease need for rescue analgesics, has a good effect on dysphagia postoperatively and doesn't produce hallucinations in children undergoing tonsillectomy.

\section{Keywords}

Peri-Tonsillar, Ketamine, Children, Analgesic

\section{Introduction}

Postoperative pain management after the surgeries with a suitable analgesic is an important issue for patients especially in pediatrics, although age specific pain evaluation tools are available, postoperative pain is still undertreated in children [1]. Postoperative pain has not only a pathophysiologic impact but also affects the quality of patients' lives. Improved pain management might therefore speed up recovery and rehabilitation and consequently decrease the time of hospitalization [2].

Surgery causes tissue damage and subsequent release of biochemical agents such as prostaglandins and histamine. These agents can then stimulate nociceptors, which will send the pain message to the central nervous system to generate the sensation of pain [3]. Moreover, neuroendocrine responses to pain can also cause hypercoagulation state and immune suppression, leading to hyperglycemia, which can delay wound healing [4].

Tonsillectomy is one of the painful operations, which is common in children that requires a potent analgesic drug to prevent this pain and complication related to it as nausea, vomiting and dysphagia to solids and liquids [5].

There are number of studies in which preincisional peritonsillar saline infiltration were used as placebo group to establish the effectiveness of peritonsillar infiltrations of other medications as tramadol [6] and bupivacaine in children undergoing tonsillectomy [7]. Opioids including morphine are sometimes used and have high efficacy to suppress post-tonsillectomy pain, but the important side effects, especially respiratory depression, have limited use of them [8].

Nonsteroidal Anti-Inflammatory Drugs (NSAIDs), including diclofenac, are also used as preventive analgesia, but they increase the risk of site-bleeding after tonsillectomy [9].

Ketamine is an anesthetic from phencyclidine family, which because of its antagonist effects on $\mathrm{N}$ methyl-D-aspartate receptors (that are involved in central 
pain sensitization) has regulatory influence on central sensitization and opium resistance. It can also band with mu receptors in the spinal cord and brain and cause analgesia. Ketamine can be utilized intravenously, intra-muscularly, epidurally, rectally, nasally and locally infiltrated [10].

Because ketamine is an NMDA receptor antagonist, it is hypothesized to prevent or reverse central sensitization and consequently reduce postoperative pain; the local anesthetic effects are likely from the blocking action on sodium channels [11]. During this study, we will assess the effectiveness of pre-incisional peritonsillar infiltration of two doses of ketamine $(0.25$ and $0.5 \mathrm{mg} / \mathrm{kg})$ on postoperative pain relief compared with peritonsillar saline and adverse effects related to ketamine infiltration in children undergoing tonsillectomy.

\section{Patients \& Methods}

After approval of Departments of Anesthesia and Otorhinolaryngology, Faculty of Medicine, Al-Azhar University, and the medical ethics committee, an informed consent was obtained from parents of each patient.

The study was conducted in the ENT operating theatre, Al-Azhar University Hospitals. A randomized prospective study was done on seventy-five patients to assess the effect of pre-incisional peritonsillar infiltration of two dose of ketamine $(0.25 \mathrm{mg} / \mathrm{kg})$ and $(0.5 \mathrm{mg} \backslash \mathrm{kg})$ on postoperative pain relief compared with peritonsillar saline and adverse effects related to ketamine infiltration in children undergoing tonsillectomy under general anesthesia.

\subsection{Inclusion Criteria}

1) ASA physical status I and II patients.

2) Age: patients from 5 - 15 years.

3) Sex: both sexes are included in this study.

4) Residence: Persons were selected from both urban and rural areas.

\subsection{Exclusion Criteria}

1) patients with ASA more than II.

2) Recent upper respiratory tract infection.

3) Evidence of any bleeding disorders.

4) History of quinsy.

5) Evidence of local pathology disturbing oral cavity as cleft palate or bifid uvula.

6) Contraindication and allergy to ketamine.

7) Inability or refusal to consent.

\subsection{Group Allocation}

Randomization was done by closed envelope method where Patients randomized into one of three test groups (25 patients in each group):

- Group A (K1): will receive preincisional peritonsillar ketamine infiltration 
$(0.25 \mathrm{mg} / \mathrm{kg})$,

- Group B (K2): will receive preincisional peritonsillar ketamine infiltration $(0.5 \mathrm{mg} / \mathrm{kg})$

- Group C (S): will receive preincisional peritonsillar normal saline.

Anesthesiologist prepared syringes containing either normal saline or the study medication for each subject.

\subsection{Anesthetic Management}

\subsubsection{Pre-Operative Preparations}

In preoperative preparation, a preoperative visit to the patients in order to take history, perform clinical examination (body systems \& air way assessment) and review preoperative laboratory investigations including complete blood picture, prothrombin time and concentration and, Written consent was taken and the patients were fasted for $6 \mathrm{~h}$ prior to surgery.

\subsubsection{Procedure}

On arrival to the operating theatre, intravenous access was established by the insertion of an intravenous $22 \mathrm{G}$ cannula. All patients were monitored with non-invasive blood pressure (BP), ECG, and pulse oximeter $\left(\mathrm{SpO}_{2}\right)$ before induction of general anesthesia (GA), capnography for end tidal $\mathrm{CO}_{2}\left(\mathrm{ETCO}_{2}\right)$ after induction of GA. Anesthesia was induced with atracurium (tracium) (0.5 $\mathrm{mg} / \mathrm{kg}$ ) and fentanyl $(1 \mathrm{mic} / \mathrm{kg}$ ) was given before ketamine (katalar) infiltration to every patient, Endotracheal intubation with appropriate size oral endotracheal tube was accomplished and lungs was mechanically ventilated at tidal volume of $6-8 \mathrm{ml} / \mathrm{kg}$, to maintain the $\mathrm{ETCO}_{2} 30-35 \mathrm{mmHg}$. After endotracheal intubation, positioning and application of mouth gag, peritonsillar infiltration was applied through the tonsillar capsule and anterior plica to all patients of three study groups that is $2 \mathrm{ml}$ ketamine $0.25 \mathrm{mg} / \mathrm{kg}$ in group-A and ketamine 0.5 $\mathrm{mg} / \mathrm{kg}$ in group-B and $2 \mathrm{ml}$ normal saline in group-C, $1 \mathrm{ml}$ per tonsil in all patients, tonsillectomy incision was started three minutes after injection. Anesthesia was maintained with oxygen $100 \%$, isoflurane $1 \%$ and atracurium $(0.1 \mathrm{mg} / \mathrm{kg})$ providing muscle relaxation every 30 minutes. Related Quality of Life (HRQL) [12]. At the end of surgery isoflurane was discontinued and after recovery of motor power, neuro-muscular blockade was reversed with neostigmine (0.04 $\left.\mathrm{mg} \cdot \mathrm{kg}^{-1}\right)$ and atropine $\left(0.02 \mathrm{mg} \cdot \mathrm{kg}^{-1}\right)$, and when the patient was fully awake the endotracheal tube was removed in lateral position and oxygen given via face mask to all patients.

Data collection and measurement:

1) Hemodynamic parameters: Heart rate and MAP were recorded at the intervals: Base line reading (before and after induction of anesthesia), and every 10 minutes till the end of surgery.

2) Ventilation parameters: Oxygen saturation and end tidal $\mathrm{CO}_{2}$ Base line reading (before and after induction of anesthesia), and every 10 minutes till the end of surgery. 
3) Post-operative patient's monitoring: After extubation, patients were shifted to post-anesthesia care unit (PACU), each patient was assessed at 15, 30 and 60 minutes postoperatively in PACU and at 2, 4, 6, 8, 1012 and 24 hours in the ward for:

a) Postoperative pain assessment by using Children's Hospital of Eastern Ontario Pain Scale (CHEOPS) established by [13].

b) The sedative condition was assessed with the Wilson sedation scale at 5,15 , 30, and 60 min after entrance to the PACU. CHEOPES was recorded only when patient modified Wilson sedation score was one [7].

\subsubsection{Incidences of Postoperative Complications as}

Blood loss, Dysphagia was graded on a scale from 0 to 4 points as (0) no dysphagia, (1) dysphagia for regular solids, (2) dysphagia for soft solids, (3) dysphagia including liquids and (4) complete dysphagia including saliva [14].

CHEOPS score of 5 or more will be given intramuscular sodium diclofenac (1 $\mathrm{mg} / \mathrm{kg}$ ) as rescue analgesic, Time of first rescue analgesic will be recorded for each patient, frequency of analgesics used over 24 hours postoperatively, Metoclopramide $(1 \mathrm{mg} / \mathrm{kg})$ intravenously will be given to patients with nausea or vomiting (Table 1).

\subsection{Statistical Analysis}

Data were statistically described in terms of mean \pm standard deviation (SD), frequencies (number of cases) and relative frequencies percentages (when Comparisons between numerical variables of three groups were done by unpaired Students test for parametric data or Mann-Whitney Rank Sum test for non-parametric data., Chi square $\left(x^{2}\right)$ test was performed. A probability value ( $\mathrm{p}$ value) less than 0.05 was considered statistically significant. All statistical calculations were done using computer programs Microsoft Excel 2007 (Microsoft Corporation, NY, and USA) and Statistical Package for the Social Science (SPSS; SPSS Inc., Chicago, IL, USA version 22) for Microsoft windows.

\section{Results}

This study was performed on seventy-five patient of both sexes of class I and II ASA physical status patients who were scheduled for elective tonsillectomy in Al-Azhar University Hospitals. Patients were randomly allocated into three groups, 25 patients in each $(\mathrm{n}=25)$ :

1) Group A (K1): will receive pre-incisional peritonsillar ketamine infiltration $(0.25 \mathrm{mg} / \mathrm{kg})$.

2) Group B (K2): will receive pre-incisional peritonsillar ketamine infiltration $(0.5 \mathrm{mg} / \mathrm{kg})$.

3) Group C (S): will receive pre-incisional peritonsillar normal saline.

\subsection{Demographic Data}

They showed no significant differences regarding age, gender and weight (Table 
2)

There were no significant differences among the groups with respect to the demographic data, duration of surgery or anesthesia, and intraoperative blood loss (Table 3).

\subsection{Hemodynamic Parameters}

Changes in Mean arterial blood pressure: As regarding hemodynamics, the mean blood pressure was significantly lower in group (K1) than group S (control group) at 20 and 30 minutes after injection of ketamine and significantly lower in group (K2) than group S (control group) at 20 and 30 minutes after injection of ketamine with no difference between group (K1) and (K2) (Table 4).

\subsection{Post-Operative Pain Assessment}

Children's Hospital Eastern Ontario Pain Scale scores (CHEOPS) were significantly higher in group S compared with group K1 and K2 (P value $<0.05$ ). Regarding the CHEOPS scores observed at all times, there was a statistically significant difference between group $\mathrm{S}$ and $\mathrm{K} 1$ ( $\mathrm{P}$ value $<0.05$ ), as well as group $\mathrm{S}$ and $\mathrm{K} 2$ ( $\mathrm{P}$ value $<0.001$ ). Group $\mathrm{K} 1$ and group $\mathrm{K} 2$ had comparable scores, which were not statistically significant $(P$ value $>0.05)$ (Table 5$)$.

There was a significant statistical difference in analgesia duration per hours and frequency of analgesics used over 24 hours between three groups, the duration was longer in group (K1) and (K2) and frequency of analgesics used over 24 hours (Table 6).

The incidence of postoperative complications regarding postoperative complications there was no significant statistical differences as regard nausea and vomiting, but the percentage of dysphagia is significantly higher in group $S$ (control group) than group (K1) and group (K2) (Table 7).

Table 1. Modified Wilson sedation scale [15].

\begin{tabular}{cc}
\hline Description & Score \\
\hline${ }^{* *}$ Oriented, eyes may be closed but can respond to "Can you tell me your name?" & 1 \\
"Can you tell me where you are right now?" & 2 \\
$*$ "Drowsy; eyes may be closed, arousable only to command: & \\
$* *$ Arousable to mild physical stimulation (ear lobe tug) \\
$* *$ Unarousable to mild physical stimulation & 3 \\
\hline
\end{tabular}

Table 2. Demographic data of patients included in the study.

\begin{tabular}{cccc}
\hline Variable & $\begin{array}{c}\text { Group K1 } \\
(\mathrm{n}=25)\end{array}$ & $\begin{array}{c}\text { Group K2 } \\
(\mathrm{n}=25)\end{array}$ & $\begin{array}{c}\text { Group S } \\
(\mathrm{n}=25)\end{array}$ \\
\hline Age (year) & $9.75 \pm 2.3$ & $8.9 \pm 2.3$ & $9.6 \pm 2.5$ \\
Weight $(\mathrm{kg})$ & $22.3 \pm 6.0$ & $21.2 \pm 6.1$ & $24.2 \pm 6.4$ \\
Sex (M/F) & $17 / 8(68 / 32)$ & $14 / 11(56 / 44)$ & $15 / 10(60 / 40)$ \\
\hline
\end{tabular}

Data expressed as mean $\pm(\mathrm{SD})$. 
Table 3. Duration of surgery, duration of anesthesia, and blood loss, for the three treatment groups.

\begin{tabular}{cccc}
\hline Variable & $\begin{array}{c}\text { Group K1 } \\
(\mathrm{n}=25)\end{array}$ & $\begin{array}{c}\text { Group K2 } \\
(\mathrm{n}=25)\end{array}$ & $\begin{array}{c}\text { Group S } \\
(\mathrm{n}=25)\end{array}$ \\
\hline Duration of surgery (min) & $30.6 \pm 6.8$ & $28.6 \pm 5.6$ & $31.0 \pm 5.4$ \\
$\begin{array}{c}\text { Duration of } \\
\text { anesthesia (min) }\end{array}$ & $36.6 \pm 6.8$ & $37.4 \pm 5.2$ & $38.7 \pm 5.8$ \\
Blood loss (ml) & $42.4 \pm 33.3$ & $45.0 \pm 21.4$ & $49.4 \pm 29.2$ \\
\hline
\end{tabular}

Data expressed as mean $\pm(\mathrm{SD})$.

Table 4. Mean blood pressure (mmhg) in three groups of the study.

\begin{tabular}{cccc}
\hline Variable & $\begin{array}{c}\text { Group K1 } \\
(\mathrm{n}=25)\end{array}$ & $\begin{array}{c}\text { Group K2 } \\
(\mathrm{n}=25)\end{array}$ & $\begin{array}{c}\text { Group S } \\
(\mathrm{n}=25)\end{array}$ \\
\hline $\begin{array}{c}\text { Preoperative mean } \\
\text { Blood Pressure }\end{array}$ & $80.35 \pm 12.15$ & $82.20 \pm 13.16$ & $84.05 \pm 13.12$ \\
$\begin{array}{c}\text { Mean blood pressure } \\
\text { after induction }\end{array}$ & $74.1 \pm 10.81$ & $77.3 \pm 13.87$ & $81.8 \pm 12.49$ \\
$\begin{array}{c}\text { Mean blood pressure } \\
\text { after injection }\end{array}$ & $82 \pm 10.89$ & $80 \pm 10.24$ & $87.4 \pm 12.57$ \\
$\begin{array}{c}\text { Mean blood pressure } \\
\text { after 10 minutes }\end{array}$ & $78.35 \pm 12.79$ & $72.15 \pm 10.18$ & $84.95 \pm 11.6$ \\
$\begin{array}{c}\text { Mean blood pressure } \\
\text { after 20 minutes }\end{array}$ & $73.25 \pm 10.68^{*}$ & $64.45 \pm 9.16^{*}$ & $82.5 \pm 10.89$ \\
$\begin{array}{c}\text { Mean blood pressure } \\
\text { after 30 minutes }\end{array}$ & $72.4 \pm 10.22^{*}$ & $70.8 \pm 13.15^{*}$ & $81.8 \pm 11.35$ \\
\hline
\end{tabular}

Data expressed as mean $\pm(\mathrm{SD}) *=\mathrm{P}$ value $<0.05$.

Table 5. CHEOPS in three groups of the study.

\begin{tabular}{lccc}
\hline Variable & $\begin{array}{c}\text { Group K1 } \\
(\mathrm{n}=25)\end{array}$ & $\begin{array}{c}\text { Group K2 } \\
(\mathrm{n}=25)\end{array}$ & $\begin{array}{c}\text { Group S } \\
(\mathrm{n}=25)\end{array}$ \\
\hline CHEOPS (30 minutes) & $4 \pm 2.5^{*}$ & $3 \pm 1.9^{*}$ & $6.5 \pm 1.0$ \\
CHEOPS (60 minutes) & $3.8 \pm 1.6^{*}$ & $2.9 \pm 1.2^{*}$ & $6.6 \pm 1.0$ \\
CHEOPS (2 hours) & $3.5 \pm 1.5^{*}$ & $3 \pm 1.4^{*}$ & $6.3 \pm 1.0$ \\
CHEOPS (4 hours) & $3.2 \pm 1.5^{*}$ & $2.6 \pm 1.4^{*}$ & $5.5 \pm 1.0$ \\
CHEOPS (6 hours) & $2.9 \pm 1.3^{*}$ & $2.5 \pm 1.58^{*}$ & $5.8 \pm 1.0$ \\
CHEOPS (8 hours) & $3.06 \pm 2.0$ & $2.3 \pm 1.5^{*}$ & $5 \pm 0.9$ \\
CHEOPS (10 hours) & $3.5 \pm 2.9$ & $3 \pm 0.99^{*}$ & $5.05 \pm 1.089$ \\
CHEOPS (12 hours) & $3.9 \pm 1.1$ & $3.52 \pm 1.38^{*}$ & $5.2 \pm 1.1$ \\
CHEOPS (24 hours) & $4 \pm 0.9$ & $3.75 \pm 1.2$ & $5 \pm 1.0$ \\
\hline
\end{tabular}

Data expressed as mean $\pm(\mathrm{SD}){ }^{*}=\mathrm{P}$ value $<0.05$. 
Table 6. Analgesia duration and frequency of analgesics used over 24 hours in three groups.

\begin{tabular}{cccc}
\hline Variable & $\begin{array}{c}\text { Group K1 } \\
(\mathrm{n}=25)\end{array}$ & $\begin{array}{c}\text { Group K2 } \\
(\mathrm{n}=25)\end{array}$ & $\begin{array}{c}\text { Group S } \\
(\mathrm{n}=25)\end{array}$ \\
\hline $\begin{array}{c}\text { Analgesia duration } \\
\begin{array}{c}\text { Frequency of } \\
\text { analgesics used }\end{array}\end{array}$ & $9.31 \pm 5.22^{\star}$ & $14.35 \pm 4.11^{\star}$ & $2.88 \pm 0.92$ \\
\hline
\end{tabular}

Data expressed as mean $\pm(S D) *=P$ value $<0.05$.

Table 7. Post-operative complications in three groups.

\begin{tabular}{cccc}
\hline Variable & $\begin{array}{c}\text { Group K1 } \\
(\mathrm{n}=25)\end{array}$ & $\begin{array}{c}\text { Group K2 } \\
(\mathrm{n}=25)\end{array}$ & $\begin{array}{c}\text { Group S } \\
(\mathrm{n}=25)\end{array}$ \\
\hline Nausea & $9(36 \%)$ & $9(36 \%)$ & $11(44 \%)$ \\
Vomiting & $3(12 \%)$ & $4(16 \%)$ & $3(12 \%)$ \\
Dysphagia & $4(16 \%)^{*}$ & $3(12 \%)^{*}$ & $18(70 \%)$
\end{tabular}

Data expressed as mean $\pm(\mathrm{SD}) *$ P value $<0.05$.

No hallucinations observed in any patient in the 3 groups.

Sedation was assessed postoperatively by Wilson sedation scale. All patients in the three study groups achieved score 1 (awake and oriented) within one hour in PACU.

\section{Discussion}

Pain control after tonsillectomy in children always remain a challenge for anesthesia and ENT physicians especially for those who are at higher risk of airway obstruction and respiratory depression [16].

Post-tonsillectomy airway complications varying from significant Oxygen desaturation to respiratory depression requiring intubation and ventilation occurred in $30 \%$ of patients with obstructive sleep apnea syndrome in a series stated by [17].

Moreover, post-tonsillectomy upper airway obstruction was reported where oral midazolam was used as pre-medication in combination with morphine for postoperative analgesia [18].

Paracetamol is a safe and effective analgesic except if used alone often Provides unsatisfactory analgesia. Non-steroidal anti-inflammatory drugs (NSAIDs) can be used for postoperative pain relief after tonsillectomy, they have no adverse effects on the airway but drugs such as ketolac, ibuprofen or ketoprofen increase the risk of reoperation for hemostasis after tonsillectomy [19]. Because of these reasons, effective treatment of post-tonsillectomy pain in Children still provide unique challenge to physician conducted a meta analysis of 35 randomized control studies to investigate postoperative analgesic properties of ketamine in pediatric patients demonstrated the safety of ketamine. Ketamine administered locally during tonsillectomy, reduces PACU pain intensity and PACU 
analgesic requirements. During systemic, local or caudal administration of ketamine, the analgesic effect of this compound was observed in the PACU period and was not associated with an opioid sparing effect [20].

In our study we assessed the effect of pre-incisional peritonsillar infiltration of ketamine $(0.25 \mathrm{mg} / \mathrm{kg})$ (group $\mathrm{K} 1)(\mathrm{n}=25)$ on postoperative pain relief compared to the peritonsillar infiltration of ketamine $(0.5 \mathrm{mg} / \mathrm{kg})$ (group K2) ( $\mathrm{n}=$ 25) on postoperative pain relief and pre-incisional peritonsillar infiltration of saline (group $\mathbf{S})(\mathrm{n}=25)$ and adverse effects related to ketamine infiltration in children undergoing tonsillectomy.

Our study showed longer duration of postoperative analgesia and lower requirements for postoperative analgesics in group (K2) and group (K1) compared to group $S$ (control group). In our study, we evaluate pain postoperatively using Children's Hospital of Eastern Ontario Pain Scale (CHEOPS) established by (13), the duration of analgesia and the frequency of analgesics used over 24 hours postoperatively.

Regarding CHEOPS score there was a statistical difference in three groups at $(0.5,1,2,4$ and 6 hours) postoperatively ( $\mathrm{p}$ value $<0.05$ ), and statistical difference between group (K2) and group (S) at (8, 10 and 12 hours) postoperatively ( $\mathrm{p}$ value $<0.05$ ), at the rest of times there is no statistical difference because the effect of rescue analgesic in group S(control group) started to appear while the ketamine group was still pain free without rescue analgesics. Moreover, the duration of analgesia postoperatively was a great statistical difference between the three groups where the time of first rescue analgesic was longer in group K2 (17.5 \pm 6.75 hours) and group K1 (11 \pm 7.95 hours) than group S (3.5 \pm 0.863 hours).

Concerning the frequency of analgesics used over 24 hours postoperatively base on ( $1 \mathrm{mg}$ diclofen $/ \mathrm{kg} \mathrm{IV})$, It was less in group K1 (0.85 \pm 0.933$)$ and group $\mathrm{K} 2(0.7 \pm 0.75)$ than group $\mathrm{S}(3 \pm 0.918)$. Moreover 12 patients in group K1 ( $\mathrm{n}=$ $25)$ and 18 patients in group $K 2(n=25)$ require no rescue analgesics in first 24 hours. Regarding modified Wilson sedation scale (Table 1), there was no statistical difference between three groups and all patient were fully awake and oriented Within 30 minutes postoperatively in PACU.

Regarding postoperative complications, Swallowed blood, pain, and direct oropharyngeal irritation may contribute to postoperative nausea and vomiting following tonsillectomy, in our study there was no significant statistical differences as regard nausea and vomiting, but the percentage of dysphagia is significantly higher in group S (control group): 18 patients (70\%) than group K1: 4 patient (16\%) and group K2: 3 patients (12\%). None of the patients required reoperation for bleeding. No hallucinations observe in any patient in the three groups.

As regard the pain, postoperative duration of analgesia and analgesic consumption, our results agree with Honarm and Reza study [21], where Seventyfive patients aged $3-12$ years, scheduled for adenotonsillectomy were divided 
into three groups of 25 each and received a local peritonsillar infiltration of $0.9 \%$ saline (group S), ketamine $(0.5 \mathrm{mg} / \mathrm{kg}$ ) (group $\mathrm{K} 1)$, or ketamine $(1 \mathrm{mg} / \mathrm{kg}$ ) (group K2). All medications were $2 \mathrm{ml}$ in volume which was applied $1 \mathrm{ml}$ per tonsil 3 min prior to tonsillectomy. The Children's Hospital of Eastern Ontario Pain Scale (CHEOPS), they found that saline group had significantly higher CHEOPS scores than ketamine group. During 24 hours after surgery 16 patients in saline group and no patients in ketamine group needed analgesics $(\mathrm{P}<0.001)$.

They concluded that a $(0.5$ or $1 \mathrm{mg} / \mathrm{kg})$ dose of ketamine given at approximately three minutes before surgery by peritonsillar infiltration provides efficient pain relief during $24 \mathrm{~h}$ after surgery without side-effects in children undergoing adenotonsillectomy. But in our study, we tried to use a lower dose of peritonsillar ketamine infiltration $(0.25 \mathrm{mg} / \mathrm{kg})$ and $(0.5 \mathrm{mg} / \mathrm{kg})$ to demonstrate if it is efficient or not in pre-emptive analgesia with expectation of least side effects [21].

As regard the different routes of admiration of ketamine and how it produces its postoperative analgesic effect, our results agree with Heidari et al. [22] who enrolled 70 children undergoing elective tonsillectomy, and divided them randomly in two groups. Patients received rectal ketamine $(2 \mathrm{mg} / \mathrm{kg})$ or rectal acetaminophen $(20 \mathrm{mg} / \mathrm{kg})$ at the end of surgery. The CHEOPS was used to estimate pain in children, they found that the ketamine group had a lower pain score at 15 minutes and 60 minutes after surgery in recovery $(6.4 \pm 0.8,7.4 \pm 1$ versus. 7.1 $\pm 1.2,7.8 \pm 1.2$ in the acetaminophen group, $\mathrm{P}<0.05)$ and one hour and two hours in the ward $(7.2 \pm 0.7,7 \pm 0.5$ vs. $7.9 \pm 1.2,7.5 \pm 1.2$ in the acetaminophen group, $\mathrm{P}<0.05)$, with no significant differences till 24 hours.

They concluded that rectal ketamine has analgesic effects, especially in the first hours after surgery in comparison with acetaminophen, and it can be an alternative analgesic with easy administration in children after tonsillectomy but still both were unsatisfactory for postoperative analgesia, which goes in line with our conclusion, but in our study the duration of analgesia was longer and the CHEOPS score in the ketamine groups was lower at all times during 24 hours postoperatively than ketamine group of Heidari et al. [22], this may be due to different route of administration in our study (peritonsillar).

Where during peritonsillar infiltration, ketamine shows its local analgesic effect by blockade of sodium and potassium channels in the peripheral nerve (tonsillar nerve). In pre-clinical studies, peripheral local ketamine was shown to have an anti-hyperalgesia effect and we use rescue analgesic on pain score 5 or more in our study. Also in consistence with our study Dal and Elven [22] showed that low dose of ketamine $(0.5 \mathrm{mg} / \mathrm{kg})$ given I.V. or peritonsillar infiltration perioperatively provides efficient pain relief without significant side effects in comparison to IV saline in children undergoing adenotonsillectomy, In our study, in distinction to the Dal and Elven [23] study we use a lower dose of ketamine (0.25 $\mathrm{mg} / \mathrm{kg})$ and use high dose of ketamine $(0.5 \mathrm{mg} / \mathrm{kg})$ we had a peritonsillar saline infiltration group. 
Our data showed that pain scores were lower in peritonsillar ketamine infiltrated groups compared with peritonsillar saline infiltration. So, we can suppose that providing significant analgesic effect after peritonsillar ketamine infiltration could possibly contribute to the effectiveness shown by ketamine infiltration [22].

Our conclusions we agreed with Honarm and Reza [21] who used peritonsillar ketamine infiltration in two doses $(0.5 \mathrm{mg} / \mathrm{kg})$ and $(1 \mathrm{mg} / \mathrm{kg})$, they concluded that a $(0.5$ or $1 \mathrm{mg} / \mathrm{kg})$ dose of ketamine given at approximately three minute before surgery by peritonsillar infiltration provides efficient pain relief during 24 hours after surgery without side-effects in children undergoing adenotonsillectomy, while in our study we used pre-incisional peritonsillar infiltration of lower dose of ketamine $(0.25 \mathrm{mg} / \mathrm{kg})$ and $(0.5 \mathrm{mg} / \mathrm{kg})$ that found peritonsillar ketamine is efficient for postoperative analgesia for 24 hours postoperatively, which decreased need for rescue analgesics, had a good effect on dysphagia postoperatively and didn't produce hallucinations in children undergoing tonsillectomy. So, it was efficient in pre-emptive analgesia with expectation of least side effects.

\section{Conclusion}

In our study, we found that preincisional peritonsillar infiltration of $0.25 \mathrm{mg} / \mathrm{kg}$ or $0.5 \mathrm{mg} / \mathrm{kg}$ of ketamine given at approximately three minutes before surgery provides efficient pain relief during $24 \mathrm{~h}$ after surgery, decrease need for rescue analgesics, has a good effect on dysphagia postoperatively and doesn't produce hallucinations in children undergoing tonsillectomy.

\section{Conflicts of Interest}

The authors declare no conflicts of interest regarding the publication of this paper.

\section{References}

[1] Astuto, M., Rosano, G., Rizzo, G., Disma, N. and di Cataldo, A. (2007) Methodologies for the Treatment of Acute and Chronic Nononcologic Pain in Children. $M i$ nerva Anestesiologica, 73, 459-465.

[2] Desborough, J.P. (2000) The Stress Response to Trauma and Surgery. British Journal of Anaesthesia, 85, 109-117. https://doi.org/10.1093/bja/85.1.109

[3] Ulius, D. and Basbaum, A.I. (2001) Molecular Mechanisms of Nociception. Nature, 413, 203-210.

[4] Kissin, I. (2005) Preemptive Analgesia at the Cross Road. Anesthesia \& Analgesia, 100, 754-756. https://doi.org/10.1213/01.ANE.0000144429.39988.9B

[5] Ravi, R. and Howell, T. (2007) Anesthesia for Pediatric Ear, Nose and Throat Surgery. Continuing Education in Anaesthesia, Critical Care \& Pain, 7, 33-37. https://doi.org/10.1093/bjaceaccp/mkm004

[6] Atef, A. and Fawaz, A.A. (2008) Peritonsillar Infiltration with Tramadol Improves Pediatric Tonsillectomy Pain. European Archives of Otorhinolaryngology, 265, 571-574. https://doi.org/10.1007/s00405-007-0479-6 
[7] Molliex, S., Haond, P., Baylot, D., Navez, M. and Elkhoury, Z. (2010) Effect of Prevs. Postoperative Tonsillar Infiltration with Local Anesthetics on Postoperative Pain after Tonsillectomy. Acta Anaesthesiologica Scandinavica, 40, 1210-1215.

[8] Romsing, J., Dstergaard, D., Drozdziewicz, D. and Ravn, G. (2000) Diclofenac or Acetaminophen for Analgesia in Pediatric Tonsillectomy in Out-Patients. Acta Anaesthesiologica Scandinavica, 44, 291-295. https://doi.org/10.1034/j.1399-6576.2000.440312.x

[9] Moiniche, S., Romsing, J., Dahl, J.B. and Tramer, M.R. (2003) Non-Steroidal AntiInflammatory Drugs and the Risk of Operative Site Bleeding after Tonsillectomy: A Quantitative Systemic Review. Anesthesia \& Analgesia, 96, 68-77. https://doi.org/10.1213/00000539-200301000-00015

[10] Murray, W.B., Yankelowitz, S.M. and Bester, H.F. (1987) Prevention of Post Tonsillectomy Pain with Analgesic Doses of Ketamine. South African Medical Journal, 72, 839-842.

[11] Fisher, K., Coderre, T.J. and Hagen, N.A. (2000) Targeting the N-Methyl Daspartate Receptor for Chronic pain Management: Preclinical Animal Studies, Recent Clinical Experience and Future Research Directions. Journal of Pain and Symptom Management, 20, 358-373. https://doi.org/10.1016/S0885-3924(00)00213-X

[12] Miller, R.D., Eriksson, L.I. and Fleisher, L.A. (2010) Miller's Anesthesia. 7th Edition, Churchill Living Stone, Philadelphia, 2757-2781.

[13] McGrath, P.J., Johnson, G. and Goodman, J. (1985) The CHEOPS: A Behavioral Scale for Rating Postoperative Pain in Children. In: Fields, H.L., Dubner, R., Cervero, F., Eds., Advances in Pain Research and Therapy, Raven Press, New York, 395-402.

[14] Cindoruk, M. and Karakan, T. (2006) Management of Cervical Esophageal Strictures with Self-Expanding Metalic Stents. The Turkish Journal of Gastroenterology, 17, 294-297.

[15] Wilson, E., David, A., MacKenzie, N. and Grant, I.S. (1990) Sedation during Spinal Anaesthesia: Comparison of Propofol and Midazolam. British Journal of Anaesthesia, 64, 48-52. https://doi.org/10.1093/bja/64.1.48

[16] O’Flaherly, J.E. and Lin, C.X. (2003) Does Ketamine or Magnesium Effect Post Tonsillectomy Pain in Children? Pediatric Anesthesia, 13, 413-421. https://doi.org/10.1046/j.1460-9592.2003.01049.x

[17] Rosen, G.M., Muckle, R., Mahowald, M.W., Goding, G.S. and Ullevig, C. (1994) Postoperative Respiratory Compromise in Children with Obstructive Sleep Apnea Syndrome: Can It Be Anticipated? Pediatrics, 93, 784-788.

[18] Negus, B.H. and Street, N.E. (1995) Midazolam-Opioid Combination and Postoperative Upper Airway Obstruction in Children. Anaesthesia and Intensive Care, 2, 232-233.

[19] Marret, E., Flahault, A., Samama, C.M. and Bonnet, F. (2003) Effects of Postoperative, Non-Steroidal, Anti-Inflammatory Drugs on Bleeding Risk after Tonsillectomy: Meta-Analysis of Randomized Controlled Trials. Anesthesiology, 98, 1497-1501. https://doi.org/10.1097/00000542-200306000-00030

[20] Dahmani, S., Michelet, D., Wood, C. and Nivoche, Y. (2011) Ketamine for Perioperative Pain Management in Children: Meta-Analysis of Randomized Controlled Studies. Paediatric Anesthesia, 21, 636-652.

[21] Honarmand, A. and Reza, M. (2008) The Preventative Analgesic Effect of Preincisional Peritonsillar Infiltration of Two Doses of Ketamine for Postoperative Pain Relief in Children Following Adenotonsillectomy. Pediatric Anesthesia, 18, 508-514. 
https://doi.org/10.1111/j.1460-9592.2008.02461.x

[22] Heidari, S.M., Mirlohi, S.Z. and Hashemi, S.J. (2012) Comparison of the Preventive Analgesic Effect of Rectal Ketamine and Rectal Acetaminophen after Pediatric Tonsillectomy. International Journal of Preventive Medicine, 3, S150-S155.

[23] Dal, D., Celebi, N., Elvan, E.G., Celiker, V. and Aypar, U. (2007) The Efficacy of Intravenous or Peritonsillar Infiltration of Ketamine for Postoperative Pain Relief in Children Following Adenotonsillectomy. Pediatric Anesthesia, 17, 263-269. 